\title{
Kishk Sa'eedi as a potential functional food for management of metabolic syndrome: A study of the possible interaction with pomegranate seed oil and/ or gum Arabic
}

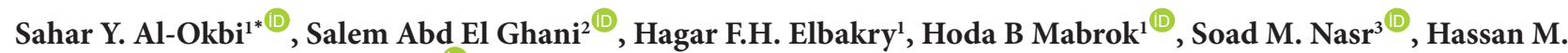 \\ Desouky ${ }^{4}$, Khaled F Mahmoud ${ }^{\mathbb{D}}$ \\ ${ }^{1}$ Nutrition and Food Sciences Department, National Research Centre, Cairo, Egypt \\ ${ }^{2}$ Dairy Sciences Department, National Research Centre, Cairo, Egypt \\ ${ }^{3}$ Department of Parasitology \& Animal Diseases, National Research Centre, Cairo, Egypt \\ ${ }^{4}$ Department of Animal Reproduction and Artificial Insemination, National Research Centre, Cairo, Egypt \\ ${ }^{5}$ Department of Food Technology, National Research Centre, Cairo, Egypt
}

\section{A R T I C L E I N F O}

Article Type:

Original Article

\section{Article History:}

Received: 11 January 2021

Accepted: 30 March 2021

\section{Keywords:}

Kishk Sa'eedi

Pomegranate seed oil

Gum Arabic

Metabolic syndrome

Steatohepatitis

Rats

\begin{abstract}
A B S T R A C T
Introduction: In the present research, the health benefits of the traditional Egyptian food called Kishk Sa'eedi (KS) and KS mixed with gum Arabic (GA) or with a mixture of GA and pomegranate seed oil (PSO) were studied in a rat model of metabolic syndrome (MS) induced by feeding high fructose high hydrogenated fat diet (HFFD).

Methods: Rats were divided into a normal control group (NC) fed on a balanced diet (Diet 1), a MS control (MSC) receiving HFFD (Diet 2), and three test groups feeding on HFFD containing KS (Diet 3), KS with GA (Diet 4), and KS with GA and PSO (Diet 5), respectively for five weeks. Biochemical and histopathological changes were assessed.

Results: Significant increase in blood glucose, plasma alanine aminotransferase (ALT) and aspartate aminotransferase (AST), urea, creatinine, uric acid, malondialdehyde (MDA), dyslipidemia and reduction in reduced glutathione (GSH) were demonstrated in MSC compared to NC $(P<0.05)$. Significant elevation in liver fat, MDA and gene expression of interleukin-6 (IL-6) with significant down-regulation of peroxisome proliferator-activated receptor (PPAR- $\alpha)$ were noticed in MSC compared to NC $(P<0.05)$. The three test diets improved plasma high-density lipoprotein-cholesterol (HDL-C), uric acid, MDA, liver PPAR- $\alpha$ and IL- 6 expression $(P<0.05)$ compared to MSC without affecting liver lipids. Blood glucose, plasma dyslipidemia, AST, creatinine and urea were improved by diet 3 and diet $5(P<0.05)$. Diet 3 elevated GSH and reduced ALT and MDA $(P<0.05)$. Histopathological changes induced by HFFD in both liver and kidney showed variable improvement by feeding the tested diets.

Conclusion: The tested diets significantly improved MS rat model with superiority to diet 3 .
\end{abstract}

Implication for health policy/practice/research/medical education:

Kishk Sa'eedi (KS) with or without gum Arabic (GA) or a mixture of both GA and pomegranate seed oil could impart protection from the incidence of metabolic syndrome with superiority to KS without any addition. Therefore, consumption of KS might be a preventive functional food for such syndrome.

Please cite this paper as: Al-Okbi SY, Abd El Ghani S, Elbakry HFH, Mabrok HB, Nasr SM, Desouky HM, et al. Kishk Sa'eedi as a potential functional food for management of metabolic syndrome: A study of the possible interaction with pomegranate seed oil and/ or gum Arabic. J Herbmed Pharmacol. 2021;10(3):319-330. doi: 10.34172/jhp.2021.37.

\section{Introduction}

Unhealthy life-style represented by high intake of sugar, especially fructose and saturated fat, accompanied by physical inactivity, are among the main causes of both metabolic syndrome (MS) and steatohepatitis (1). MS is a cluster of changes that could lead to cardiovascular diseases (CVDs) and diabetes mellitus type 2. Such changes include insulin resistance, hypertriglyceridemia, central obesity, hypertension, hyperglycemia, dyslipidemia, and fatty liver. Previously, it was assumed that kidney dysfunction 
was included as a component of MS, but this association has not yet been completely established (2). This might be due to the assumption that intake of high-fat highfructose diet might induce MS, obesity, CVDs, and kidney dysfunction $(3,4)$. Management of the aforementioned changes could certainly inhibit progression to diabetes, heart diseases, and morbidity (5-7). Non-alcoholic steatohepatitis (NASH) is the hepatic component of MS (8), which denotes accumulation of liver fat with inflammation and initiation of fibrosis that ultimately can lead to hypertriglyceridemia, hyperglycemia and CVD.

It is proposed that functional foods could ameliorate the changes induced by unhealthy life-style represented by consumption of high-sugar high-fat diet, which may be one of the main causes of MS, NASH, and kidney dysfunction. Egyptian traditional food, Kishk Sa'eedi (KS), which is a sun-dried mixture of fermented wheat product (burghul) and milk ethnically used in Upper Egypt could have health benefits towards the aforementioned diseases due to the presence of useful probiotics and their metabolites (9). Gum Arabic (GA) is a dry gummy exudate from the stem and branches of Acacia senegal. It is a branchedchain complex of the polysaccharides that might serve as prebiotic to enhance beneficial microflora, and claimed to possess hepato-, reno- and cardio-protective effects (10). Pomegranate seed oil (PSO) contains a high percent of punicic acid, which is the structure isomer of conjugated linolenic acid, and to which the health benefits of PSO were ascribed. The seed also contains oleic and linoleic acid (11). So both PSO and GA were selected to be studied in the present research because they have shown previously to possess health benefits related to MS.

The objective of the present work was to study the health benefits of functional foods represented by KS, with or without GA, or a mixture of GA and PSO in a rat model of MS with steatohepatitis and kidney dysfunction. This rat model was induced by feeding a diet high in fructose and hydrogenated fat and containing cholesterol and cholic acid.

\section{Materials and Methods}

Plant materials

GA (Acacia senegal, family fabaceae) was purchased from a local market, Egypt. KS was obtained from a local market from different areas in Giza, Egypt. Pomegranate fruit (Punica granatum, family: Lythraceae) was purchased from a local market, Giza, Egypt.

\section{Preparation of pomegranate seed and its oil}

Whole pomegranate fruits were weighed, peeled off, and the seeds were separated and squeezed by fruit juicer. The hard parts of the seed were washed, cleaned, and dried in a hot air oven at $40^{\circ} \mathrm{C}$. The dried seeds were weighed, crushed, and subjected to continuous extraction by soxhlet apparatus using petroleum ether $\left(40-60^{\circ} \mathrm{C}\right)$ as a solvent.
After complete extraction, the solvent was volatilized under reduced pressure using a rotary evaporator at a temperature not exceeding $40^{\circ} \mathrm{C}$, and the oil was obtained.

Microencapsulation of pomegranate seed oil (PSO)

PSO was microencapsulated by two layers of sodium alginate and GA. Then it was freeze-dried. To confirm the inclusion of the oil perfectly in the capsule, encapsulation efficiency was determined according to a previous method (12). Encapsulated PSO was subjected to scanning electron microscopy (SEM) to determine the particle size.

Determination of the proximate composition of KS

KS has a round and irregular shape. The purchased KS samples from different regions were mixed equally, dried in a hot air oven at $40^{\circ} \mathrm{C}$, and reduced into fine powder for determination of moisture, protein, fat, and ash according to AOAC (13). Carbohydrates (available + non available) were calculated by differences.

Animals

Male adult albino rats were obtained from the Animal House of National Research Centre, Cairo, Egypt, and maintained on balanced diet for acclimatization till they reached 170-180 g body weight. Animals were kept individually in stainless steel cages; water and food were given ad-libitum with 12 hours light/dark cycle.

\section{Diets}

Five experimental diets were prepared (Table 1); a balanced diet (Diet 1) and a high fructose-high fat diet containing both cholesterol and cholic acid (HFFD) and devoid of fibers (Diet 2). HFFD containing 10\% KS (Diet $3)$, HFFD supplemented by a mixture of KS (10\%) and GA (5\%) (Diet 4), and HFFD containing a mixture of KS (10\%), GA (5\%), and PSO (1\%) (Diet 5) were prepared as the test diets.

HFFD was prepared similar to previous researches (1416) with some modifications to induce MS associated with NASH and kidney dysfunction.

\section{Experimental procedure}

Forty rats were divided into five equal groups. The first was a normal control (NC) group, where the rats received a balanced diet (Diet 1). The second group was MS control (MSC), where the rats were fed on Diet 2 (HFFD). Groups three, four, and five were fed on diet 3, 4, and 5, respectively. During the experiment, body weight and food intake were monitored once a week. At the end of the experiment that continued for five weeks total food intake, body weight gain, and food efficiency ratio (Body weight gain/total food intake) were calculated. Fasting blood glucose was measured using a supersensor Glucometer (GlucoDr $\left.{ }^{\mathrm{TM}}\right)$ at the early morning, where blood samples were drawn from rat tail. Blood uric acid was assessed using a uricometer 
Table 1. Composition of the experimental diets $(\mathrm{g} / 100 \mathrm{~g})$

\begin{tabular}{|c|c|c|c|c|c|}
\hline \multirow{2}{*}{ Ingredients } & \multicolumn{5}{|c|}{ Type of diet } \\
\hline & Balanced diet (Diet 1) & HFFD (Diet2) & Diet 3 & Diet 4 & Diet 5 \\
\hline Casein & 12 & 12 & 9.58 & 9.58 & 9.58 \\
\hline Sunflower oil & 10 & 1.07 & 1.00 & 1 & - \\
\hline Starch & 68.5 & 12.66 & 5.15 & 0.15 & - \\
\hline Fructose & - & 49.59 & 49.59 & 49.59 & 49.59 \\
\hline Cellulose & 5 & - & - & - & - \\
\hline Mineral mixture & 3.5 & 3.5 & 3.5 & 3.5 & 3.5 \\
\hline Vitamin mixture & 1 & 1 & 1 & 1 & 1 \\
\hline Hydrogenated oil & - & 18.93 & 18.93 & 18.93 & 18.93 \\
\hline Cholesterol & - & 1 & 1 & 1 & 1 \\
\hline Cholic acid & - & 0.25 & 0.25 & 0.25 & 0.25 \\
\hline KS & - & - & 10 & 10 & 10 \\
\hline GA & - & - & - & 5 & 5 \\
\hline PSO microencapsulation & - & - & & - & $1.15^{*}$ \\
\hline
\end{tabular}

HFFD: High fructose-high fat dietl; GA, Gum Arabic; KS, Kishk Sa'eedi; PSO, Pomegranate seed oil.

$* 1.15 \mathrm{~g}$ from pomegranate seed oil (PSO) microcapsules= $1 \mathrm{~g}$ PSO.

(EasyTouch, GCU, Taiwan). Blood samples were collected from the eye vein of anaesthetized rats after an overnight fast, in heparinized tubes. Plasma was separated by centrifugation at $3500 \mathrm{rpm}$ for 15 minutes. Lipid profile represented by plasma total cholesterol (TC), high density lipoprotein cholesterol (HDL-C), low density lipoprotein cholesterol (LDL-C), and triglycerides (TG) were determined as previously mentioned (17-20). Atherogenic index (AI) was calculated (TC /HDL-C) to indicate the risk factor for CVDs (21). Liver functions were assessed by measuring activities of plasma aspartate aminotransferase (AST) and alanine aminotransferase (ALT), as outlined previously (22). Urea and creatinine were estimated as representative of kidney function $(23,24)$. Plasma reduced glutathione (GSH) was determined by enzymelinked immune-sorbent assay (ELISA) (SinoGeneclon Biotech Co., Ltd). Rats were dissected for immediate separation and weighing of liver, heart and kidney. The liver was cut into 4 pieces. The kidney and the first piece from the liver were collected from all experimental groups and fixed in neutral buffered formalin (10\%), washed, dehydrated, cleared and embedded in paraffin. Paraffin blocks were sectioned at $\sim 5 \mu \mathrm{m}$ thickness and stained with hematoxylin and eosin (H\&E) (25). The slides were examined for histopathological alterations under a light microscope (Model CX41, Olympus, Japan). The second piece of the liver was rinsed in saline and kept frozen at $-20^{\circ} \mathrm{C}$ for determination of total lipid content adopting the previous procedure $(26,27)$. The third piece of the liver was rinsed in phosphate-buffered saline with $\mathrm{pH}$ 7.4 for immediate estimation of liver malondialdehyde (MDA). Liver MDA was estimated as a marker of lipid peroxidation (28). The fourth piece of liver was used for extraction of RNA for subsequent assessment of peroxisome proliferator-activated receptor (PPAR)- $\alpha$ and interleukin-6 (IL-6) gene expression adopting real time polymerase chain reaction (RT-PCR).

Determination of total lipid content

The liver tissue was homogenized with dichloromethane/ methanol (2/1) 20 times the volume of the tissue sample (1 $\mathrm{g}$ liver tissue in $20 \mathrm{~mL}$ of solvent mixture). After dispersion, the whole mixture was agitated for 15-20 minutes in an orbital shaker at room temperature. The homogenate was centrifuged at $3000 \mathrm{rpm}$ to recover the liquid phase. The liquid phase was transferred to a clean tube. The solvent was washed with saline ( $4 \mathrm{ml}$ for $20 \mathrm{~mL}$ ). After vortexing for a few seconds, the mixture was centrifuged at low speed (2000 rpm) to separate the two phases. The upper phase was removed and discarded. The lower phase (dichloromethane containing lipid) was transferred to a clean pre-weighed tube. Dichloromethane was evaporated under a nitrogen stream. The tubes were re-weighed and the difference accounted for total fat in $1 \mathrm{~g}$ liver tissue. Liver fat was calculated as $\mathrm{g} / 100 \mathrm{~g}$ liver tissue $(26,27)$.

Gene expression analysis by RT-PCR

Total RNA was isolated from liver tissue with PureLink ${ }^{\circledR}$ RNA Mini Kit (Ambion ${ }^{\circledR}$ Life Technologies ${ }^{\mathrm{TM}}$ ) according to the manufacturer's instructions. RNA concentrations were measured with a NanoDrop spectrophotometer. The purity of the extracted RNA was assessed by the $A_{260 \mathrm{~nm}}$ / $\mathrm{A}_{280 \mathrm{~nm}}$ ratio. The cDNA was synthesized from $2.0 \mu \mathrm{g}$ of total RNA in $20 \mu \mathrm{L}$ reaction with the High Capacity cDNA Reverse Transcription kit (Ambion ${ }^{\circledR}$ Life Technologies ${ }^{\mathrm{TM}}$ ) according to the manufacturer's instructions.

Real-time PCR was performed with a Rotor-Gene ${ }^{\circledR}$ MDx instrument. The RT-PCR reaction mixture $(20 \mu \mathrm{L})$ contained $1 \mu \mathrm{L}$ template cDNA, $1 \times$ the EvaGreen ${ }^{\circledR}$ PCR master mix (HOT FIREPol ${ }^{\circledast}$ EvaGreen ${ }^{\circledR}$ qPCR Mix Plus, Solis BioDyne ${ }^{\mathrm{TM}}$ ) and $0.2 \mu \mathrm{M}$ of the primer pairs. Primer pairs sequence used for PPAR- $\alpha$ and interleukin-6 (IL-6) 
Table 2. Primers used for real-time polymerase chain reaction amplifications

\begin{tabular}{|c|c|c|c|}
\hline Target genes & Sequences & Annealing temperature & PCR product size (bp) \\
\hline PPAR $\alpha$ & $\begin{array}{l}\left.\text { FW (5'- TTCGGAAACTGCAGACCT - } 3^{\prime}\right) \\
\left.\text { RW (5'- TTAGGAACTCTCGGGT - } 3^{\prime}\right)\end{array}$ & $55^{\circ} \mathrm{C}$ & 442 \\
\hline IL-6 & $\begin{array}{l}\left.\text { FW (5'- TGATGGATGCTTCCAAACTG }-3^{\prime}\right) \\
\left.\text { RW (5'- GAGCATTGGAAGTTGGGGTA - } 3^{\prime}\right)\end{array}$ & $60^{\circ} \mathrm{C}$ & 230 \\
\hline GAPDH & $\begin{array}{l}\left.\text { FW (5'- GTATTGGGCGCCTGGTCACC - } 3^{\prime}\right) \\
\left.\text { RW (5'- CGCTCCTGGAAGATGGTGATGG }-3^{\prime}\right)\end{array}$ & $60^{\circ} \mathrm{C}$ & 324 \\
\hline
\end{tabular}

bp: Base pair.

gene expression analysis were adapted from the literature $(29,30)$; primers' sequence is presented in Table 2. PCR reactions were performed using the following protocol: $95^{\circ} \mathrm{C}$ for $15 \mathrm{~min}, 45$ cycles of 15 seconds at $95^{\circ} \mathrm{C}, 60$ seconds at $55^{\circ} \mathrm{C}$ or $60^{\circ} \mathrm{C}, 20$ seconds at $72^{\circ} \mathrm{C}$ and melting curve program $\left(60-95^{\circ} \mathrm{C}\right)$. PCR water was used instead of cDNA templates as a negative control. The relative expression of the target genes was calculated using $2^{-\Delta \Delta C T}$ method (31); the target gene expression was normalized to the expression of the house-keeping gene GAPDH.

\section{Statistical analysis}

The results of the animal experiment were expressed as the mean \pm SE and they were analyzed statistically using the one-way analysis of variance ANOVA followed by Tukey test using Statistical Package of Social Sciences (SPSS) software version 22. In all cases, $P \leq 0.05$ was used as the criterion of statistical significance.

\section{Results}

The proximate composition of KS (Table 3) as g/100 g sample was 24.2, 9, 7.4, 0.7, and 58.7 for protein, ash, moisture, fat, and total carbohydrates (Available and nonavailable carbohydrates), respectively.

The yield of pomegranate seed and its oil

Pomegranate seed is white and small presents inside the red fleshy pomegranate arils. $6858 \mathrm{~g}$ fruits (arils) gave 365 g dry seeds. Thus, fresh pomegranate fruit (arils) contains $5.3 \%$ dry seeds. $365 \mathrm{~g}$ seeds gave $58 \mathrm{~g}$ of PSO. Hence the yield of PSO was $16 \%$. Then, the pomegranate fruit (arils) gives approximately $0.85 \%$ oil from its seeds.

Encapsulation efficiency and scanning electron

Table 3. Proximate composition of Kishk Sa'eedi (g/100 g)

\begin{tabular}{lc}
\hline Parameter & $\%$ \\
\hline Protein & 24.2 \\
Fat & 0.7 \\
Ash & 9 \\
Moisture & 7.4 \\
Total carbohydrates (Available and non-available & 58.7 \\
carbohydrates) & \\
\hline
\end{tabular}

microscopy of the encapsulated PSO

The extraction of the encapsulated PSO indicated that $1 \mathrm{~g}$ capsule contained $0.87 \mathrm{~g}$ of PSO. SEM showed the presence of encapsulated PSO in the micro range (Figure 1).

\section{Result of the animal experiment}

Nutritional parameters are shown in Table 4. It could be noticed that final body weight and body weight gain of MSC control were higher than NC without a significant difference with an insignificant reduction in total food intake and a significant increase in food efficiency ratio. HFFD supplemented with either KS or KS+GA+PSO produced an insignificant reduction of body weight gain and final body weight compared to NC and MSC. HFFD+Kishk+GA produced a significant reduction in body weight gain and final body weight compared to MSC, while only body weight gain showed a significant reduction from NC. Food efficiency demonstrated a significant reduction in all test groups compared to MSC.

Relative organ weight/body weight percent and liver fat percent of different experimental groups are shown in Table 5. There were insignificant changes of relative kidney and heart weight/body weight percent among different groups. Liver fat and liver/body weight percent of MSC showed significant increase compared to the NC. Liver fat and liver/body weight percent of the different test

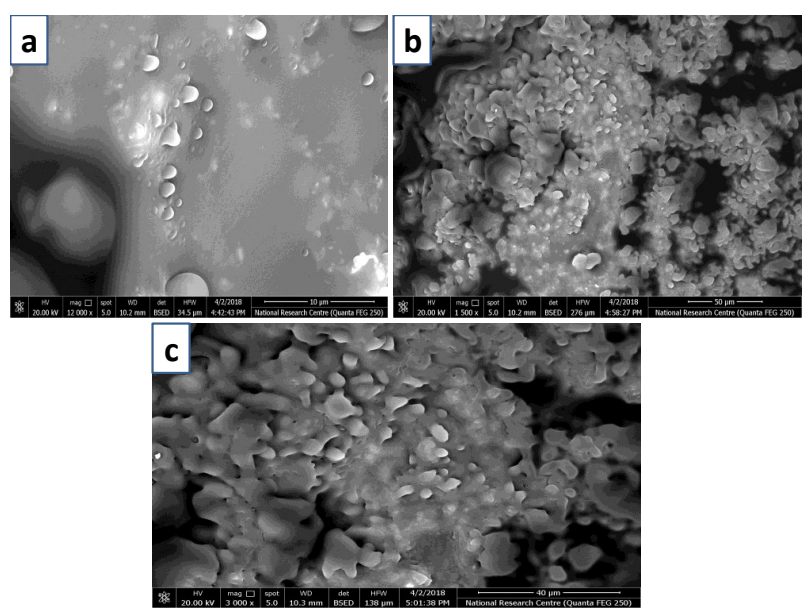

Figure 1. Scanning electron microscopy measure of the encapsulated pomegranate seed oil (a: $10 \mu \mathrm{m}, \mathrm{b}: 50 \mu \mathrm{m}$ and c: $40 \mu \mathrm{m}$ ). 
groups showed insignificant changes from MSC.

Plasma lipid profile and blood glucose are compiled in Table 6. MSC showed significant increases in blood glucose and plasma TG, TC, LDL-C, and AI with a significant reduction in HDL-C compared to NC. Supplementation of diet with either KS or KS+GA+PSO produced a significant improvement of all these parameters while diet containing KS+GA showed only significant improvement in HDL-C and AI. Blood uric acid and liver and kidney function of the experimental groups are shown in Table 7. Blood uric acid and all parameters of liver and kidney functions were significantly increased on feeding HFFD (MSC) compared to NC. All these parameters were improved significantly on feeding HFFD supplemented by KS. Feeding HFFD diet supplemented by KS+GA produced only significant reduction of uric acid. Significant improvements of uric, urea and creatinine and the activity of AST were noticed on feeding HFFD containing Kishk+GA+PSO.

Plasma GSH and both plasma and hepatic MDA of different experimental groups are shown in Table 8 . Significant elevations of plasma and hepatic MDA with significant reduction of plasma GSH were noticed in MSC compared to NC. Significant improvements of these parameters were shown on supplementation with KS, while only a significant improvement in plasma MDA was demonstrated on feeding either of the other two tested diets.

PPAR $\alpha$ and IL- 6 genes were expressed in the liver of all experimental groups (Table 9). PPARa gene expression was significantly down-regulated in MSC compared with the

Table 4. Nutritional parameters of different experimental groups

\begin{tabular}{|c|c|c|c|c|c|}
\hline Groups & Initial body weight (g) & Final body weight (g) & Body weight gain (g) & Total food intake (g) & Food efficiency ratio \\
\hline NC & $172.6^{\mathrm{a}} \pm 8.25$ & $238.4^{\mathrm{ab}} \pm 6.1$ & $65.8^{\mathrm{a}} \pm 6.4$ & $413.9^{a b} \pm 11.51$ & $0.16^{a} \pm 0.016$ \\
\hline HFFD Control & $171.9^{\mathrm{a}} \pm 7.37$ & $246.3^{b} \pm 6.64$ & $74.4^{\mathrm{a}} \pm 5.8$ & $357.63^{a} \pm 24.76$ & $0.210^{\mathrm{b}} \pm 0.023$ \\
\hline HFFD+KS & $172.9^{\mathrm{a}} \pm 5.64$ & $232.1^{\mathrm{ab}} \pm 7.7$ & $59.3^{\mathrm{ab}} \pm 3.7$ & $422.5^{a b} \pm 30.62$ & $0.140^{\mathrm{a}} \pm 0.011$ \\
\hline $\mathrm{HFFD}+\mathrm{KS}+\mathrm{GA}$ & $172.6^{a} \pm 6.4$ & $223^{a} \pm 6$ & $50.4^{\mathrm{b}} \pm 2.4$ & $404.4^{\mathrm{ab}} \pm 22.87$ & $0.125^{\mathrm{a}} \pm 0.008$ \\
\hline $\mathrm{HFFD}+\mathrm{KS}+\mathrm{GA}+\mathrm{PSO}$ & $172.1^{\mathrm{a}} \pm 6.67$ & $231.8^{\mathrm{ab}} \pm 7.3$ & $59.6^{\mathrm{ab}} \pm 6.9$ & $439.3^{b} \pm 21.65$ & $0.136^{\mathrm{a}} \pm 0.015$ \\
\hline
\end{tabular}

Data are means $\pm S E ; n=8$. In the same column similar letters mean insignificant difference within groups while different letters mean significant difference at $P<0.05$.

NC: Normal control fed on balanced diet, HFFD: High fructose-high fat diet, GA: Gum Arabic, PSO: Encapsulated pomegranate seed oil, KS: Kishk Sa'eedi.

Table 5. Relative organ weight/body weight $(\mathrm{g} \%)$ and liver fat percentage of different experimental groups

\begin{tabular}{|c|c|c|c|c|}
\hline Groups & $\begin{array}{l}\text { Liver weight/ } \\
\text { body weight } \%\end{array}$ & $\begin{array}{l}\text { Liver fat } \\
\text { (g/100 g liver tissue) }\end{array}$ & $\begin{array}{l}\text { Heart weight/ } \\
\text { body weight } \%\end{array}$ & $\begin{array}{l}\text { Kidney weight/ } \\
\text { body weight } \%\end{array}$ \\
\hline NC & $3.4^{a} \pm 0.12$ & $4.32^{a} \pm 0.23$ & $0.32^{a} \pm 0.05$ & $0.59^{\mathrm{a}} \pm 0.09$ \\
\hline HFFD Control & $4.6^{b} \pm 0.21$ & $10.22^{\mathrm{bc}} \pm 1.00$ & $0.28^{a} \pm 0.05$ & $0.72^{\mathrm{a}} \pm 0.03$ \\
\hline HFFD+KS & $4.24^{b} \pm 0.15$ & $10.02^{b} \pm 0.50$ & $0.28^{a} \pm 0.04$ & $0.68^{a} \pm 0.03$ \\
\hline $\mathrm{HFFD+KS+GA}$ & $4.73^{b} \pm 0.31$ & $11.76^{c} \pm 0.609$ & $0.36^{a} \pm 0.02$ & $0.73^{a} \pm 0.02$ \\
\hline $\mathrm{HFFD}+\mathrm{KS}+\mathrm{GA}+\mathrm{PSO}$ & $4.7^{b} \pm 0.42$ & $11.72^{\mathrm{bc}} \pm 0.33$ & $0.3^{\mathrm{a}} \pm 0.01$ & $0.65^{\mathrm{a}} \pm 0.04$ \\
\hline
\end{tabular}

Data are means $\pm \mathrm{SE} ; \mathrm{n}=8$. In the same column similar letters mean insignificant difference within groups while different letter means significant difference at $P<0.05$.

NC: Normal control fed on balanced diet, HFFD: High fructose-high fat diet, GA: Gum Arabic, PSO: Encapsulated pomegranate seed oil, KS: Kishk Sa'eedi.

Table 6. Blood glucose and plasma lipid profile $(\mathrm{mg} / \mathrm{dL})$ of different experimental groups

\begin{tabular}{|c|c|c|c|c|c|c|}
\hline Groups & Glucose & TG & T-C & HDL-C & LDL-C & Al \\
\hline NC & $72.75^{a} \pm 2.76$ & $47.14^{\mathrm{a}} \pm 1.79$ & $71.12^{\mathrm{a}} \pm 1.07$ & $43.33^{\mathrm{a}} \pm 0.91$ & $18.52^{\mathrm{a}} \pm 1.21$ & $1.65^{\mathrm{a}} \pm 0.04$ \\
\hline HFFD Control & $86.63^{b} \pm 2.20$ & $90.03^{b} \pm 3.63$ & $121.49^{b} \pm 5.81$ & $35.53^{b} \pm 1.97$ & $67.95^{b} \pm 5.27$ & $3.42^{b} \pm 0.20$ \\
\hline $\mathrm{HFFD+KS}$ & $72.38^{\mathrm{a}} \pm 2.43$ & $50.88^{a} \pm 1.83$ & $95.23^{c} \pm 2.89$ & $46.99^{a c} \pm 1.60$ & $38.06^{c} \pm 3.09$ & $2.03^{c} \pm 0.10$ \\
\hline $\mathrm{HFFD}+\mathrm{KS}+\mathrm{GA}$ & $84.8^{b} \pm 1.26$ & $87.98^{b} \pm 2.44$ & $130.20^{b} \pm 5.19$ & $48.84^{c} \pm 1.96$ & $58.84^{b} \pm 5.88$ & $2.67^{c} \pm 0.14$ \\
\hline $\mathrm{HFFD}+\mathrm{KS}+\mathrm{GA}+\mathrm{PSO}$ & $75.50^{\mathrm{a}} \pm 1.49$ & $59.22^{c} \pm 1.96$ & $100.08^{c} \pm 2.37$ & $44.47^{\mathrm{ac}} \pm 2.19$ & $43.76^{c} \pm 3.5$ & $2.25^{c} \pm 0.15$ \\
\hline
\end{tabular}

Data are means $\pm \mathrm{SE} ; \mathrm{n}=8$. In the same column similar letters mean insignificant difference within groups while different letters mean significant difference at $P<0.05$.

NC: Normal control fed on balanced diet, HFFD: High fructose-high fat diet, GA: Gum Arabic, PSO: Encapsulated pomegranate seed oil, KS: Kishk Sa'eedi , TG: Triglycerides, TC: Total cholesterol, HDL-C: High density lipoprotein cholesterol, LDL-C: Low density lipoprotein cholesterol, Al: Atherogenic index $=\mathrm{T}-\mathrm{C} / \mathrm{HDL}-\mathrm{C}$ 
Al-Okbi et al

Table 7. Liver and kidney functions and uric acid of different experimental groups

\begin{tabular}{|c|c|c|c|c|c|}
\hline \multirow{2}{*}{ Groups } & \multicolumn{2}{|c|}{ Liver functions } & \multicolumn{2}{|c|}{ Kidney functions } & \multirow{2}{*}{ Uric acid $(\mathrm{mg} / \mathrm{dL})$} \\
\hline & AST(IU/L) & $\operatorname{ALT}(I U / L)$ & Urea (mg/dL) & Creatinine (mg/dL) & \\
\hline NC & $23.24^{\mathrm{a}} \pm 1.14$ & $12.61^{\mathrm{a}} \pm 0.89$ & $29.08^{\mathrm{a}} \pm 2.41$ & $0.25^{\mathrm{a}} \pm 0.02$ & $1.27^{\mathrm{a}} \pm 0.11$ \\
\hline HFFD Control & $40.42^{b} \pm 1.16$ & $21.24^{b} \pm 0.93$ & $91.94^{b} \pm 2.97$ & $0.65^{b} \pm 0.03$ & $5.26^{b} \pm 0.30$ \\
\hline $\mathrm{HFFD}+\mathrm{KS}$ & $30.29^{c} \pm 0.79$ & $16.86^{\mathrm{c}} \pm 1.10$ & $66.49^{c} \pm 1.54$ & $0.55^{c} \pm 0.02$ & $2.54^{c} \pm 0.14$ \\
\hline $\mathrm{HFFD}+\mathrm{KS}+\mathrm{GA}$ & $41.67^{b} \pm 0.88$ & $21.86^{b} \pm 0.77$ & $84.14^{\text {bd }} \pm 1.54$ & $0.63^{b d} \pm 0.02$ & $2.78^{c} \pm 0.14$ \\
\hline $\mathrm{HFFD}+\mathrm{KS}+\mathrm{GA}+\mathrm{PSO}$ & $37.17^{d} \pm 0.56$ & $21.24^{\mathrm{b}} \pm 1.07$ & $77.77^{d} \pm 4.56$ & $0.57^{c d} \pm 0.03$ & $2.76^{c} \pm 0.13$ \\
\hline
\end{tabular}

Data are means $\pm \mathrm{SE} ; \mathrm{n}=8$. In the same column similar letters mean insignificant difference within groups while different letters mean significant difference at $P<0.05$.

NC: Normal control fed on balanced diet, HFFD: High fructose-high fat diet, GA: Gum Arabic, PSO: Encapsulated pomegranate seed oil, KS: Kishk Sa'eedi; ALT: Alanine aminotransferase, AST: Aspartate aminotransferase

Table 8. Plasma GSH and both plasma and hepatic MDA of different experimental groups

\begin{tabular}{llll}
\hline Groups & Plasma GSH $(\mu \mathrm{g} / \mathrm{mL})$ & Plasma MDA $(\mathrm{nmol} / \mathrm{mL})$ & Hepatic MDA $(\mathrm{nmol} / \mathrm{g}$ tissue) \\
\hline NC & $3.71^{\mathrm{a}} \pm 0.24$ & $3.21^{\mathrm{a}} \pm 0.26$ & $58.16^{\mathrm{a}} \pm 4.79$ \\
HFFD Control & $3.07^{\mathrm{b}} \pm 0.10$ & $7.40^{\mathrm{b}} \pm 0.70$ & $105.12^{\mathrm{b}} \pm 8.98$ \\
HFFD+KS & $3.61^{\mathrm{ac}} \pm 0.09$ & $4.85^{\mathrm{cd}} \pm 0.33$ & $60.56^{\mathrm{a}} \pm 3.86$ \\
HFFD+KS+GA & $3.46^{\mathrm{bc}} \pm 0.09$ & $6.05^{\mathrm{c}} \pm 0.40$ & $101.04^{\mathrm{b}} \pm 2.67$ \\
HFFD+KS+GA+PSO & $3.30^{\mathrm{bc}} \pm 0.13$ & $4.76^{\mathrm{d}} \pm 0.35$ & $93.79^{\mathrm{b}} \pm 2.48$ \\
\hline
\end{tabular}

Data are means $\pm \mathrm{SE} ; \mathrm{n}=8$. In the same column similar letters mean insignificant difference within groups while different letters mean significant difference at $P<0.05$.

NC: Normal control fed on balanced diet, HFFD: High fructose-high fat diet, GA: Gum Arabic, PSO: Encapsulated pomegranate seed oil, KS: Kishk Sa'eedi, GSH: Reduced glutathione, MDA: malondialdehyde.

healthy control rats. Intake of KS alone or in combination with GA induced a significant up-regulation of the mRNA expression of PPARa by 3.1 and 3.5 fold-change than MSC, respectively. Feeding diet containing PSO + KS + GA increased PPARa gene expression significantly to 2.28 fold compared to MSC. The mRNA expression of IL-6 was significantly up-regulated in the liver of MSC. However, different treatments have reversed the up-regulation in the expression of IL-6. Gene expression of IL- 6 level was

Table 9. The relative expression of PPARa and IL-6 genes in liver of different experimental groups

\begin{tabular}{lcc}
\hline \multirow{2}{*}{ Groups } & \multicolumn{2}{c}{ Relative expression } \\
\cline { 2 - 3 } & \multicolumn{1}{c}{ IL-6 } & PPAR $\alpha$ \\
\hline NC & $0.03 \pm 0.024^{\mathrm{b}}$ & $3.11 \pm 0.086^{\mathrm{b}}$ \\
HFFD control & $1.00 \pm 0.111^{\mathrm{a}}$ & $1.00 \pm 0.114^{\mathrm{a}}$ \\
HFFD+KS & $0.31 \pm 0.034^{\mathrm{c}}$ & $3.12 \pm 0.398^{\mathrm{b}}$ \\
HFFD+KS+ GA & $0.53 \pm 0.022^{\mathrm{e}}$ & $3.55 \pm 0.172^{\mathrm{b}}$ \\
HFFD+KS+ GA+PSO & $0.56 \pm 0.019^{\mathrm{e}}$ & $2.28 \pm 0.205^{\mathrm{c}}$ \\
\hline
\end{tabular}

The values are means $\pm \mathrm{SE}$. In the same column similar letters mean insignificant difference within groups while different letters mean significant difference at $P<0.05$.

NC: Normal control fed on balanced diet, HFFD: High fructose-high fat diet, GA: Gum Arabic, PSO: Encapsulated pomegranate seed oil, KS: Kishk Sa'eedi, PPAR- $\alpha$ : Peroxisome proliferator-activated alpha receptor, IL-6: Interleukin-6.

The mRNA expression of PPAR $\alpha$ and IL- 6 is normalized with housekeeping gene (GAPDH); values are fold change of HFFD control group. significantly lowered by 3.2 and 1.9 fold after treatment with KS alone or combined with GA. The combination of KS, GA, and PSO down-regulated the IL-6 expression by 1.79 fold compared to MSC.

Histopathological changes of the liver of different experimental groups are shown in Figure 2. NC showed a normal appearance of hepatic tissue (A). Microscopic examination of the livers of the rats fed on HFFD, as control group, revealed severe and diffuse scattered fatty change (steatosis) throughout the hepatic parenchyma in most of the examined cases (B1). The hepatic blood vessels appeared dilated and congested. In few cases, marked subcapsular and interstitial hemorrhages were seen (B2). Liver of the rats fed on HFFD with KS showed a variable degree of fatty change, where half of the treated animals showed mild to moderate fatty changes (C1). The other half revealed severe and diffuse fatty changes (C2). Liver of the rats fed on HFFD with KS and GA showed diffuse and severe fatty change and vacuolar degeneration in half of the examined cases (D1). Moreover, extensive subcapsular and interstitial hemorrhages were noticed (D2). One case showed mild and focal fatty change, two cases revealed multiple areas (periportal and midzonal) of moderate fatty change (D3). The hepatic blood vessels were also dilated and engorged with blood. Liver of the rats fed on HFFD with KS, GA, and PSO showed diffuse and severe fatty changes in most of the examined cases (E1). In few cases (two) a mild degree of fatty change in 
the midzonal and periportal hepatocytes fatty change (E2) were seen. The pericentral hepatocytes appeared relatively swollen with dark eosinophilic cytoplasm and vesicular nuclei.

Histopathological changes of the kidneys of different groups are illustrated in Figure 3. The kidney of the control group demonstrated normal structure of renal parenchyma (A). Microscopic examination of the kidneys of the rats fed on HFFD as control revealed the presence of acidophilic homogenous casts within the lumen of the renal tubules (B1) meanwhile numerous dark acidophilic granular masses (droplets) were also observed in some tubules, whereas the apical portion of the epithelial cells was protruded and sloughed (B2). In some cases, the epithelial lining of renal tubules showed vacuolar degeneration (B3). The renal blood vessels appeared dilated and congested, in addition to interstitial haemorrhages (B4). The microscopic examination of kidney of the rat fed on HFFD with KS showed vacuolar degeneration of the epithelial lining of renal tubules of most of examined cases. Meanwhile, other tubules appeared cystically dilated and were lined by flattened epithelial cells (C1). Moreover, the occurrence of eosinophilic homogenous masses within the lumen of renal tubules was also observed in half of the examined cases. In some tubules, the epithelial cells were swollen with granular cytoplasm, and sloughing of the apical part into the lumens resulting in the presence of eosinophilic droplets within the lumens of tubules (C2).
The peritubular blood capillaries were also dilated and congested. The microscopic examination of the kidney of the rat fed on HFFD with KS and GA showed the presence of eosinophilic granular masses (droplets) within the lumen of renal tubules in half number of examined group (Figure 3D). At the same time, the epithelial cells appeared swollen (increase in size) with protrusion of the apical portion with subsequent sloughing into the lumen. Meanwhile, the remaining cases appeared within the normal limit. However, dilatation and congestion of renal blood vessels were noticed. The microscopic examination of kidney of two cases of rats fed on HFFD with KS, GA, and PSO showed the presence of eosinophilic granular masses (droplets) within the lumen of renal tubules (Figure 3E1). The epithelial lining of some renal tubules revealed degenerative changes, mainly vacuolar degeneration (Figure 3E2). The histological picture of the remaining cases was more or less similar to the normal control group.

\section{Discussion}

The present work deals with studying the beneficial effects of functional foods represented by KS and its combination with either GA or GA with PSO in MS model associated with steatohepatitis and kidney dysfunction. Such model was induced in rats by a high-fructose high-fat diet deficient in fiber and supplemented by cholesterol and cholic acid. Feeding this diet succeeded in inducing the required changes, which agreed with previous works

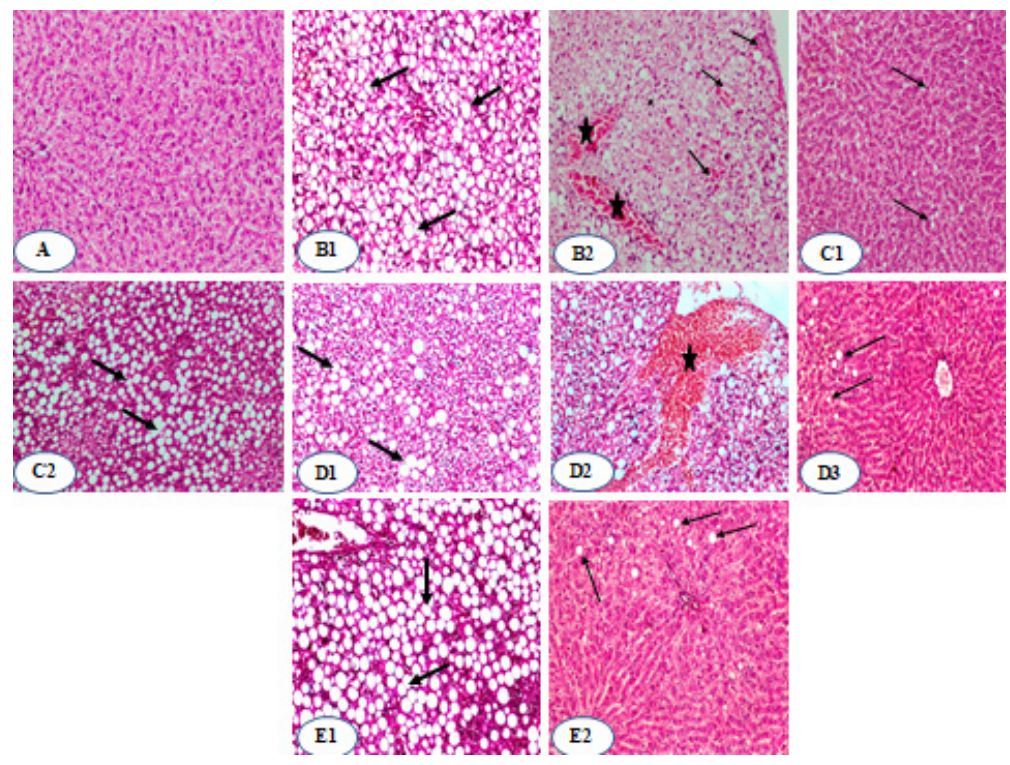

Figure 2. Histopathology of liver of different experimental groups. A: Liver of normal control group showed normal structure of hepatic parenchyma (H\&E X100). B1, B2: HFFD as MSC, B1 demonstrated severe and diffuse scattered fatty change (arrows); H\&E X100, B2 showed subcapsular and interstitial hemorrhages (arrows) in addition to dilatation and congestion of hepatic blood vessels (asterisks); H\&E X100. C1, C2: HFFD+KS, C1 illustrated mild and focal fatty change (arrows); H\&E X100, C2 showing severe and diffuse scattered fatty change (arrows); H\&E X100. D1, D2, D3: HFFD+KS+GA, D1 demonstrated severe and diffuse scattered fatty change (arrows); H\&EX100, D2 showed area of extensive hemorrhage (asterisks); H\&E X100, D3 illustrated moderate midzonal and periportal fatty change (arrows); H\&E X100, E1, E2: HFFD+KS+GA+ PSO, E1 showed severe and diffuse fatty change (arrows); H\&E X100, E2 exhibited Liver with mild degree of fatty change in periportal hepatocytes (arrows); H\&E X100.

HFFD: High fructose-high fat diet, MSC: Control rats with metabolic syndrome, GA: Gum Arabic, PSO: Encapsulated pomegranate seed oil, KS: Kishk Sa'eedi. 


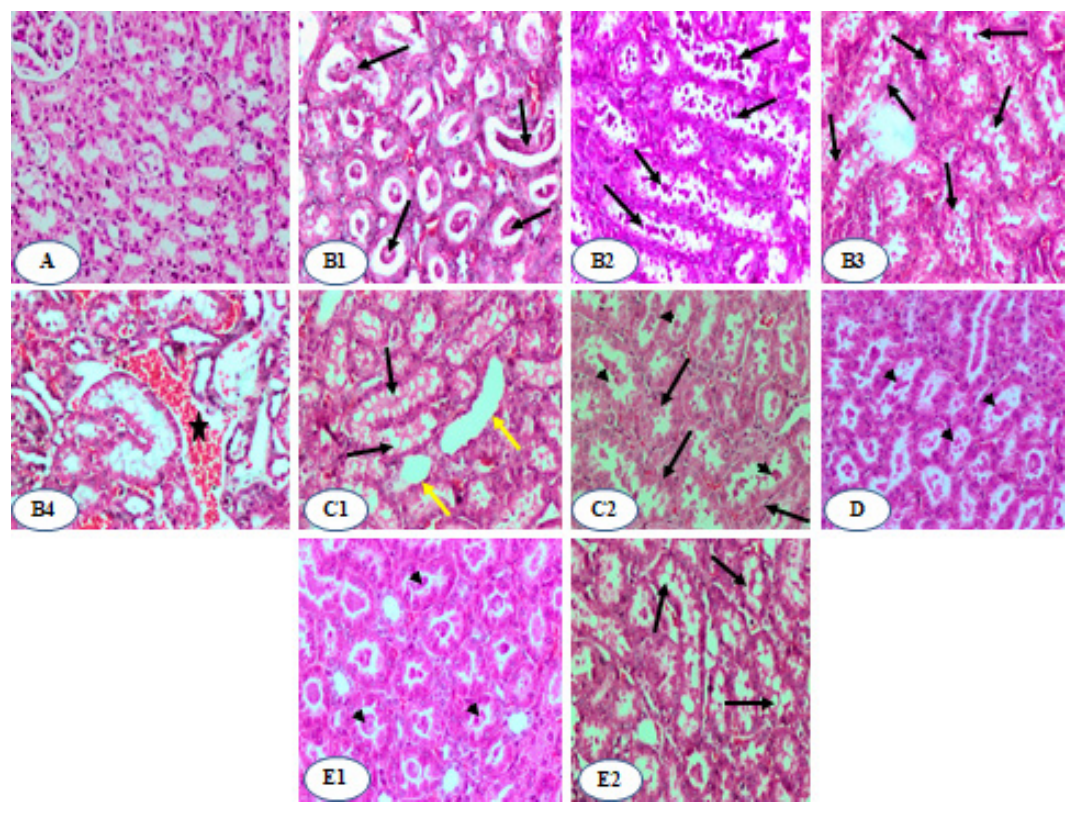

Figure 3. Histopathology of kidney of different experimental groups. A: kidney of normal control group, showed normal structure of renal parenchyma (H\&EX200). B1-B4: kidney of rats fed on HFFD as MSC, B1 demonstrated renal casts within the tubules (arrows); H\&E,X200, B2 showed the presence of numerous dark acidophilic granular masses as droplets (arrows); H\&EX200, B3 exhibited vacuolar degeneration of epithelial lining of some tubules (arrows); H\&EX200, B4 illustrated interstitial haemorrhage (asterisk) in between renal tubules (H\&E X200). C1,C2: kidney of rat fed on HFFD with Kishk, C1 showed vacuolar degeneration of epithelial lining of some tubules (black arrows). Others appeared cystically dilated with flattened epithelium (yellow arrows); H\&EX200, C2 demonstrated sloughing of the apical portion of epithelial cells (arrows) with formation of eosinophilic droplets in the lumens of tubules (head arrows); H\&EX100. D: kidney of rat fed on HFFD with KS and GA showing occurrence of eosinophilic droplets (head arrows) in the lumens of tubules (H\&EX200). E1,E2: kidney of rats fed on HFFD with KS, GA and PSO, E1 illustrated occurrence of eosinophilic droplets (head arrows) in the lumens of tubules (H\&EX200), E2 showed vacuolar degeneration of epithelial lining of renal tubules (arrows); H\&EX200.

HFFD: High fructose-high fat diet, MSC: Control rats with metabolic syndrome, GA: Gum Arabic, PSO: Encapsulated pomegranate seed oil, KS: Kishk Sa'eedi.

that used similar diets $(15,32,33)$. Dietary components in the prepared diet, especially fructose, enhance lipid accumulation in the liver due to stimulation of hepatolipogenesis and inhibition of fatty acid beta-oxidation with simultaneous induction of insulin resistance, oxidative stress, CVD risks, and renal dysfunction (34).

Inflammatory processes and liver death during NASH might be related to the accumulation of liver fat leading to high oxidative stress and inflammation that may induce damage to proteins and hepatocytes. Elevated liver cytokines like IL-6, tumor necrosis factor- $\alpha$, and insulin resistance might participate in induction of NASH. PPAR in the cell nucleus, which is essential for insulin to elucidate its effect, was reported to stop working during fatty liver leading to insulin resistance that may result in liver cell inflammation and scarring (35).

KS is an Egyptian traditional food, which is a fermented milk-wheat (burghul) mixture stored as dried balls (3638). KS is a unique balanced food containing $B$ vitamins and could possess remedial effects due to its content of lactic acid probiotic (36). The composition of KS in the present study showed high protein and ash with low-fat percentage. The proximate composition of KS greatly varied according to milk components, processing technique, date of production, and other environmental factors. The proximate composition of commercial KS showed $8-13 \%$ moisture, $9-23 \%$ protein, $1-12 \%$ fat, 31 $66 \%$ carbohydrates, $1 \%-2 \%$ crude fibers, and $6-11 \%$ ash $(37,39-41)$. The protein content of some samples of KS is very high and hence, the amino acid content is excellent. Kishk contains high concentrations of phenylalanine, threonine, isoleucine, leucine, arginine, valine, tyrosine, and lysine, but it has low amounts of tryptophan and sulphur-containing amino acids $(9,37)$.

The high content of ash in Kishk denoted the high level of minerals represented by calcium, magnesium, potassium, iron, manganese, and selenium as reported previously (42). Trace elements like manganese and selenium could potentiate the antioxidant enzyme synthesis in the body. The health benefit of KS might be ascribed to the presence of probiotics' metabolites (9) associated with microbial fermentation process. A previous work (43) showed the presence of conjugated linoleic acid in KS that might also have added health benefits. Polyunsaturated and monounsaturated fatty acids were reported in samples of KS (42), which possess hypocholesterolemic, antiinflammatory, and cardioprotective effects. Although some studies showed low amounts of tryptophan and sulphur-containing amino acids in KS $(9,37)$, a previous work (43) reported the presence of sulphur containing amino acids, which might enhance production of GSH in the body and improve the antioxidant status (44), leading 
to cardio- hepato- and reno-protective effects.

KS was reported previously to significantly improve TC, TG, HDL-C, LDL-C, and atherogenic index in rats (45), which agreed with the present study. Non-available carbohydrates in KS, represented by dietary fibers, have a role in improving lipid profile through preventing absorption of cholesterol. Beneficial lactic acid bacteria associated with fermentation process, constituted 25-43\% of the total bacterial flora in KS (L. casei, L. plantarum, L. brevis) and some samples contained a very low number of yeasts (9). The beneficial microorganisms and their metabolites are considered probiotics, while burghul, with its content of fibers, could work as prebiotic that could enhance beneficial microbiota in the colon. So both probiotic and prebiotic, together named synbiotics, are capable of imparting healthy effects. Therefore, KS might be considered as functional foods. Lactobacilli, a probiotic in Kishk was reported previously to reduce the CVDs risks through anti-inflammatory and lipid lowering effects $(46,47)$. Some lactobacilli interfere with enterohepatic circulation of bile salts with simultaneous combination to cholesterol leading to reduction of intestinal absorption of cholesterol with subsequent reduction of its blood level $(48,49)$. The aforementioned anti-inflammatory effect might also participate in the reno- and hepato- protective effects.

GA was reported to alleviate adverse effects of chronic renal failure in human by improving urea and creatinine levels (50). However other experiments on rats could not confirm this effect. A controversy in literature concerning the effect of GA on lipid profile in both human and rats exists, but there is a suggestion that it produces hypocholesterolemic effect in rats. GA was demonstrated to possess adverse effects on electrolyte balance and vitamin D in mice (10). GA is rich in soluble non-viscous fibers (11), which might be the cause of its proposed hypocholesterolemic effect. GA was claimed to possess anti-inflammatory activity towards intestinal mucosa (51) and anti-oxidant effect (52). Thence, cardioand reno-protective effects were proposed $(53,54)$. GA was ineffective in ameliorating hepatocellular damage in cholestasis induced by fenofibrate in rats (55). The GA, used in a concentration up to $10 \%$ in drinking water, failed to show any antioxidant activity (56). This controversy in literature may explain the reduced health benefits demonstrated on the inclusion of GA in the diet in the present work.

PSO is a rich source of tocopherols, especially the gamma homologue, and a lower level of tocotrienols and plastochromanol-8 as antioxidant components (57). Punicic acid, a structure isomer of conjugated linolenic acid, is present in PSO. Also, oleic and linoleic acids are among the fatty acids in PSO (11). These fatty acids possess hypolipidemic and cardio-protective effects. PSO was prepared as microcapsules to prevent any interaction with the different food ingredients and components on inclusion in the diet and in the GIT.

During the present study, it could be seen from the biochemical results that blood glucose was improved to reach the normal level on supplementation of either KS or KS with GA and PSO, while no effect was noticed on feeding KS with GA. Both TC and LDL-C were significantly reduced on treatment with either KS or KS with GA and PSO, but still not reaching the normal level. However, no effect was noticed on feeding KS with GA. Plasma triglycerides showed significant improvement on feeding diets containing KS or KS with GA and PSO, which reached the normal level only in the first case. However, the diet supplemented with KS+ GA did not show any improvement. These changes might reflect a bad (negative or antagonistic) effect of GA that might abolish the improving effect of KS, while adding PSO could restore the beneficial effect of KS to a certain limit. Although GA inclusion produced no beneficial effect towards TC, TG, and LDL-C, however, HDL-C and AI demonstrated significant improvement on feeding the different test diets showing KS to be superior followed by KS with GA and PSO, then KS with GA, which pointed to cardio-protective effect of the three test diets with variable degrees.

Hepatic MDA and reduced GSH were improved on supplementation of KS, while plasma MDA was significantly improved on feeding either of the three test diets; KS was superior. Improvement of these parameters reflects an antioxidant effect that prevents inflammatory condition with subsequent cardio-, hepato-, and renoprotective effects, which could be observed by improving AI, liver, and kidney function in the present study. No significant improvement on liver fat percentage was noticed on feeding either of the tested diets on biochemical basis. However, the histopathology of liver showed improvement in fat deposition in 50\% of the rats fed on KS diet, 37.5\% in those fed on KS with GA diet, and 25\% in the rats fed on KS with GA and PSO. Histopathological changes in kidney were improved by different degrees when feeding the different tested diets.

PPAR- $\alpha$ gene expression negatively correlates with insulin resistance and severity of NASH (58). PPAR- $\alpha$ regulates expression of the genes involved in fatty acid $\beta$-oxidation and cytokines (IL-1 $\beta$, IL-6, IL-8, TNFa, and COX-2) (59,60). PPAR- $\alpha$ down-regulates the expression of IL-6 via negative cross-talk with NF-kappa B and activator protein-1 (61). PPAR- $\alpha$ and IL- 6 were improved in feeding different test diets pointed to the antiinflammatory activity and hepatoprotective effects of such diets with superiority of KS diet in case of IL- 6 and KS+ GA concerning PPAR- $\alpha$. Though the three tested diets could not reduce the liver fat content, however, they could significantly down-regulate IL- 6 and up-regulate PPAR- $\alpha$, which lead to reduced insulin resistance and inflammation. This may point to the prevention of progression of fatty liver to steatohepatitis with simultaneous prevention of 
induction of CVDs and diabetes.

\section{Conclusion}

Based on biochemical analysis of plasma and liver, gene expression study, and histopathology of liver and kidney, it could be concluded that cardio-, hepato-, and renoprotective effects might be afforded on feeding KS with or without either GA or GA with PSO. KS was superior, followed by KS with GA and PSO; meanwhile, KS with GA had the least effect.

\section{Acknowledgements}

The work was completely carried out in National Research Centre, Egypt.

\section{Authors' contributions}

ASY and AEGS designed the study, ASY wrote the manuscript with the interpretation of the results. EHFH implemented the animal experiment, biochemical analysis, extraction of PSO and microcapsules, analysis of KS, followed electronic microscopy of microcapsules, and wrote the first draft of the manuscript related to her implemented part. MHB carried out the molecular biology part and wrote the first draft of such part. NSM and DHM implemented the histopathology part and described related results. MKF prepared the microcapsules. All authors read and approved the final version and agreed to publish it.

\section{Conflict of interests}

None to be declared.

\section{Ethical considerations}

The animal experiment was confirmed by the Medical Research Ethics Committee, National Research Centre, Cairo, Egypt (Agreement for project No. 1104010106) and followed the recommendations of the National Institute of Health Guide for Care and Use of Laboratory animals (Publication No-85-23, revised 1985). The number of rats in each group was reduced to the least for ethical purpose without affecting statistical requirements. Rats were anesthetized at the end of the experiment to minimize their suffering.

\section{Funding/Support}

This work was financed by National Research Centre, Egypt (Grant No. 1104010106).

\section{References}

1. Yki-Järvinen H. Non-alcoholic fatty liver disease as a cause and a consequence of metabolic syndrome. Lancet Diabetes Endocrinol. 2014;2(11):901-10. doi: 10.1016/s22138587(14)70032-4.

2. Ramesh Prasad GV. Metabolic syndrome and chronic kidney disease: current status and future directions. World J Nephrol. 2014;3(4):210-9. doi: 10.5527/wjn.v3.i4.210.
3. Francisqueti FV, Minatel IO, Ferron AJT, Bazan SGZ, Silva VDS, Garcia JL, et al. Effect of gamma-oryzanol as therapeutic agent to prevent cardiorenal metabolic syndrome in animals submitted to high sugar-fat diet. Nutrients. 2017;9(12):1299. doi: 10.3390/nu9121299.

4. Rodríguez-Monforte M, Sánchez E, Barrio F, Costa B, Flores-Mateo G. Metabolic syndrome and dietary patterns: a systematic review and meta-analysis of observational studies. Eur J Nutr. 2017;56(3):925-47. doi: 10.1007/s00394016-1305-y.

5. Mahalingaiah S, Diamanti-Kandarakis E. Targets to treat metabolic syndrome in polycystic ovary syndrome. Expert Opin Ther Targets. 2015;19(11):1561-74. doi: 10.1517/14728222.2015.1101067.

6. Hoffman EL, VonWald T, Hansen K. The metabolic syndrome. S D Med. 2015;Spec No:24-8.

7. Samson SL, Garber AJ. Metabolic syndrome. Endocrinol Metab Clin North Am. 2014;43(1):1-23. doi: 10.1016/j. ecl.2013.09.009.

8. Zhang X. NAFLD related-HCC: the relationship with metabolic disorders. Adv Exp Med Biol. 2018;1061:55-62. doi: 10.1007/978-981-10-8684-7_5.

9. Tamime AY, O'Connor TP. Kishk-a dried fermented milk/cereal mixture. Int Dairy J. 1995;5(2):109-28. doi: 10.1016/0958-6946(95)92205-i.

10. Ali BH, Ziada A, Blunden G. Biological effects of gum Arabic: a review of some recent research. Food Chem Toxicol. 2009;47(1):1-8. doi: 10.1016/j.fct.2008.07.001.

11. Trichur Khabeer S, Prashant A, Haravey Krishnan M. Dietary fatty acids from pomegranate seeds (Punica granatum) inhibit adipogenesis and impact the expression of the obesity-associated mRNA transcripts in human adipose-derived mesenchymal stem cells. J Food Biochem. 2019;43(3):e12739. doi: 10.1111/jfbc.12739.

12. Bae EK, Lee SJ. Microencapsulation of avocado oil by spray drying using whey protein and maltodextrin. J Microencapsul. 2008;25(8):549-60. doi: $10.1080 / 02652040802075682$.

13. Association of Official Agricultural Chemists (AOAC). Official Methods of Analysis of the Association of Official Analytical Chemists. 17th ed. Arlington, Virginia, USA: AOAC; 2000.

14. Kawasaki T, Igarashi K, Koeda T, Sugimoto K, Nakagawa $\mathrm{K}$, Hayashi S, et al. Rats fed fructose-enriched diets have characteristics of nonalcoholic hepatic steatosis. J Nutr. 2009;139(11):2067-71. doi: 10.3945/jn.109.105858.

15. Al-Okbi SY, El-Qousy SM, El-Ghlban S, Moawad HF. Role of borage seed oil and fish oil with or without turmeric and alpha- tocopherol in prevention of cardiovascular disease and fatty liver in rats. J Oleo Sci. 2018;67(12):1551-62. doi: 10.5650/jos.ess 18064 .

16. Panchal SK, Poudyal H, Iyer A, Nazer R, Alam A, Diwan $\mathrm{V}$, et al. High-carbohydrate high-fat diet-induced metabolic syndrome and cardiovascular remodeling in rats. J Cardiovasc Pharmacol. 2011;57(1):51-64. doi: 10.1097/ FJC.0b013e3181feb90a.

17. Allain CC, Poon LS, Chan CS, Richmond W, Fu PC. Enzymatic determination of total serum cholesterol. Clin Chem. 1974;20(4):470-5.

18. Burstein M, Scholnick HR, Morfin R. Rapid method for the isolation of lipoproteins from human serum by precipitation 
with polyanions. J Lipid Res. 1970;11(6):583-95.

19. Wieland H, Seidel D. A simple specific method for precipitation of low density lipoproteins. J Lipid Res. 1983;24(7):904-9.

20. Fossati P, Prencipe L. Serum triglycerides determined colorimetrically with an enzyme that produces hydrogen peroxide. Clin Chem. 1982;28(10):2077-80.

21. Marrugat J, Elosua R, Covas MI, Molina L, Rubiés-Prat J. Amount and intensity of physical activity, physical fitness, and serum lipids in men. The MARATHOM Investigators. Am J Epidemiol. 1996;143(6):562-9. doi: 10.1093/ oxfordjournals.aje.a008786.

22. Reitman S, Frankel S. A colorimetric method for the determination of serum glutamic oxalacetic and glutamic pyruvic transaminases. Am J Clin Pathol. 1957;28(1):56-63. doi: 10.1093/ajcp/28.1.56.

23. Fawcett JK, Scott JE. A rapid and precise method for the determination of urea. J Clin Pathol. 1960;13(2):156-9. doi: 10.1136/jcp.13.2.156.

24. Bartels H, Böhmer M, Heierli C. [Serum creatinine determination without protein precipitation]. Clin Chim Acta. 1972;37:193-7. doi: 10.1016/0009-8981(72)90432-9.

25. Suvarna KS, Layton C, Bancroft JD. Bancroft's Theory and Practice of Histological Techniques. 8th ed. London, UK: Elsevier Ltd; 2019. p. 672.

26. Folch J, Lees M, Sloane Stanley GH. A simple method for the isolation and purification of total lipides from animal tissues. J Biol Chem. 1957;226(1):497-509.

27. Cequier-Sánchez E, Rodríguez C, Ravelo AG, Zárate R. Dichloromethane as a solvent for lipid extraction and assessment of lipid classes and fatty acids from samples of different natures. J Agric Food Chem. 2008;56(12):4297303. doi: 10.1021/jf073471e.

28. Satoh K. Serum lipid peroxide in cerebrovascular disorders determined by a new colorimetric method. Clin Chim Acta. 1978;90(1):37-43. doi: 10.1016/0009-8981(78)90081-5.

29. Hwang SJ, Kim JH, Shim JW, Kim DS, Jung HL, Park MS, et al. Peroxisome proliferator-activated receptor-gamma expression in the lung tissue of obese rats. Yonsei Med J. 2011;52(3):495-501. doi: 10.3349/ymj.2011.52.3.495.

30. Khan HA, Abdelhalim MA, Alhomida AS, Al Ayed MS. Transient increase in IL- $1 \beta$, IL- 6 and TNF- $\alpha$ gene expression in rat liver exposed to gold nanoparticles. Genet Mol Res. 2013;12(4):5851-7. doi: 10.4238/2013.November.22.12.

31. Livak KJ, Schmittgen TD. Analysis of relative gene expression data using real-time quantitative PCR and the 2(-Delta Delta C(T)) Method. Methods. 2001;25(4):402-8. doi: 10.1006/meth.2001.1262.

32. Al-Okbi SY, Hussein AMS, Elbakry HFH, Fouda KA, Mahmoud KF, Hassan ME. Health benefits of fennel, rosemary volatile oils and their nano-forms in dyslipidemic rat model. Pak J Biol Sci. 2018;21(7):348-58. doi: 10.3923/ pjbs.2018.348.358.

33. Al-Okbi SY, Amin MA, Mohamed AEA, Edris AE, Sharaf OM, Mabrok HB, et al. Basil essential oil and its nanoemulsion mitigate non alcoholic steatohepatitis in rat model with special reference to gut microbiota. J Oleo Sci. 2020;69(8):913-27. doi: 10.5650/jos.ess20067.

34. Johnson RJ, Segal MS, Sautin Y, Nakagawa T, Feig DI, Kang $\mathrm{DH}$, et al. Potential role of sugar (fructose) in the epidemic of hypertension, obesity and the metabolic syndrome, diabetes, kidney disease, and cardiovascular disease. Am J Clin Nutr. 2007;86(4):899-906. doi: 10.1093/ajcn/86.4.899.

35. Al-Okbi SY. Role of nutraceuticals in prevention of nonalcoholic fatty liver. In: Goyal MR, Chauhan DN, eds. Plantand Marine- Based Phytochemicals for Human Health: Attributes, Potential, and Use Apple Academic Press, Taylor and Francis; 2019. p. 131-49.

36. Abd-el-Malek Y, Demerdash M. Egyptian Kishk. In: Handbook of Indigenous Fermented Foods. New York, NY: Marcel Dekker; 1993. p. 295-9.

37. Morcos SR, Hegazi SM, Ell-Damhougy SI. Egyptian bouza. In: Steinkraus KH, ed. Handbook of Indigenous Fermented Foods. New York, NY: Marcel Dekker; 1993. p. 421-5.

38. Mahmoud SA. Egyptian Kishk. In: Steinkraus KH, ed. Handbook of Indigenous Fermented Foods. New York, NY: Marcel Dekker; 1993. p. 295-9.

39. El-Sadek GM, Zawahry MR, Mahmoud SA, Abd ElMotteleb L. Chemical composition of Egyptian Kishk. Indian J Dairy Sci. 1958;11:67-75.

40. Abou-Donia SA. Egyptian fresh fermented milk products. N Z J Dairy Sci Technol. 1984;19(1):7-18.

41. Attia IA, Khattab AA. Microbiological and chemical studies on Kishk. Alexandria Science Exchange. 1985;6(1):63-71.

42. Tamime AY, Barclay MN, McNulty D, O'Connor TP. Kishk-a dried fermented milk/cereal mixture. 3. Nutritional composition. Lait. 1999;79(4):435-48. doi: 10.1051/ lait:1999436.

43. Bahgaat WK, Abd El Ghani S. Comparison of amino acids and fatty acids profiles of Egyptian Kishk: dried wheat based fermented milk mixture as functional food. Am J Food Technol. 2017;12(1):43-50. doi: 10.3923/ajft.2017.43.50.

44. Townsend DM, Tew KD, Tapiero H. Sulfur containing amino acids and human disease. Biomed Pharmacother. 2004;58(1):47-55. doi: 10.1016/j.biopha.2003.11.005.

45. Ali RFM. Hypocholesterolemic effects of diets containing different levels of Kishk as a dried fermented milkwhole wheat mixture in experimental rats. J Ethn Foods. 2016;3(2):117-23. doi: 10.1016/j.jef.2016.01.009.

46. Al-Okbi SY, Mohamad DA, Hamed TE, Afifi AA, Mohamad $\mathrm{SH}$. Reduction of the risk of cardiovascular diseases through dietary mixtures and probiotic. Med J Cairo Univ. 2010;78(1):129-37.

47. Ha CG, Cho JK, Lee CH, Chai YG, Ha Y, Shin SH. Cholesterol lowering effect of Lactobacillus plantarum isolated from human feces. J Microbiol Biotechnol. 2006;16(8):1201-9.

48. DeRodasBZ, GillilandSE,MaxwellCV.Hypocholesterolemic action of Lactobacillus acidophilus ATCC 43121 and calcium in swine with hypercholesterolemia induced by diet. J Dairy Sci. 1996;79(12):2121-8. doi: 10.3168/jds. S0022-0302(96)76586-4.

49. Begley M, Hill C, Gahan CG. Bile salt hydrolase activity in probiotics. Appl Environ Microbiol. 2006;72(3):1729-38. doi: 10.1128/aem.72.3.1729-1738.2006.

50. Suliman SM, Hamdouk MI, Elfaki MB. GA fiber as a supplement to low protein diet in chronic renal failure patients. In: Sudan Association of Physicians, 17th Conference, Friendship Hall, Khartoum, Sudan; 2000. p. 21-3.

51. Gamal el-din AM, Mostafa AM, Al-Shabanah OA, AlBekairi AM, Nagi MN. Protective effect of arabic gum against acetaminophen-induced hepatotoxicity in mice. 
Pharmacol Res. 2003;48(6):631-5. doi: 10.1016/s10436618(03)00226-3.

52. Ali AA, Ali KE, Fadlalla AE, Khalid KE. The effects of gum arabic oral treatment on the metabolic profile of chronic renal failure patients under regular haemodialysis in Central Sudan. Nat Prod Res. 2008;22(1):12-21. doi: 10.1080/14786410500463544.

53. Abd-Allah AR, Al-Majed AA, Mostafa AM, Al-Shabanah OA, Din AG, Nagi MN. Protective effect of arabic gum against cardiotoxicity induced by doxorubicin in mice: a possible mechanism of protection. J Biochem Mol Toxicol. 2002;16(5):254-9. doi: 10.1002/jbt.10046.

54. Al-Majed AA, Abd-Allah AR, Al-Rikabi AC, Al-Shabanah OA, Mostafa AM. Effect of oral administration of Arabic gum on cisplatin-induced nephrotoxicity in rats. J Biochem Mol Toxicol. 2003;17(3):146-53. doi: 10.1002/jbt.10072.

55. Cindoruk M, Kerem M, Karakan T, Salman B, Akin O, Alper $M$, et al. Peroxisome proliferators-activated alpha agonist treatment ameliorates hepatic damage in rats with obstructive jaundice: an experimental study. BMC Gastroenterol. 2007;7:44. doi: 10.1186/1471-230x-7-44.

56. Ali BH. Does gum Arabic have an antioxidant action in rat kidney? Ren Fail. 2004;26(1):1-3. doi: 10.1081/jdi120028536

57. Trela A, Szymańska R. Less widespread plant oils as a good source of vitamin E. Food Chem. 2019;296:160-6. doi: 10.1016/j.foodchem.2019.05.185.

58. Francque S, Verrijken A, Caron S, Prawitt J, Paumelle R, Derudas B, et al. PPARa gene expression correlates with severity and histological treatment response in patients with non-alcoholic steatohepatitis. J Hepatol. 2015;63(1):164-73. doi: 10.1016/j.jhep.2015.02.019.

59. Inoue I, Goto S, Mizotani K, Awata T, Mastunaga T, Kawai $\mathrm{S}$, et al. Lipophilic HMG-CoA reductase inhibitor has an anti-inflammatory effect: reduction of MRNA levels for interleukin-1beta, interleukin-6, cyclooxygenase-2, and p22phox by regulation of peroxisome proliferator-activated receptor alpha (PPARalpha) in primary endothelial cells. Life Sci. 2000;67(8):863-76. doi: 10.1016/s00243205(00)00680-9.

60. Cunard R, Ricote M, DiCampli D, Archer DC, Kahn DA, Glass CK, et al. Regulation of cytokine expression by ligands of peroxisome proliferator activated receptors. J Immunol. 2002;168(6):2795-802. doi: 10.4049/jimmunol.168.6.2795.

61. Delerive P, De Bosscher K, Besnard S, Vanden Berghe W, Peters JM, Gonzalez FJ, et al. Peroxisome proliferatoractivated receptor alpha negatively regulates the vascular inflammatory gene response by negative cross-talk with transcription factors NF-kappaB and AP-1. J Biol Chem. 1999;274(45):32048-54. doi: 10.1074/jbc.274.45.32048. 